\title{
Lessons learned from operating a pre-commercialisation field-testing platform for innovative non-sewered sanitation in Durban, South Africa
}

\author{
RC Sindall', R Cottingham², P Arumugam 1 , SJ Mercer'1, C Sutherland ${ }^{3}$, N Alcock ${ }^{2}$, CA Buckley ${ }^{1+}$ and G Gounden ${ }^{4}$ \\ ${ }^{1}$ Water, Sanitation \& Hygiene Research \& Development Centre, University of KwaZulu-Natal, Durban 4041, South Africa \\ ${ }^{2}$ Khanyisa Projects, Durban 4001, South Africa \\ ${ }^{3}$ Built Environment and Development Studies, University of KwaZulu-Natal, Durban 4041, South Africa \\ ${ }^{4}$ eThekwini Water and Sanitation, Durban 4000, South Africa \\ ${ }^{+}$deceased
}

The Engineering Field Testing Platform (EFTP) was designed to provide an opportunity for technology developers (TDs) to test non-sewered sanitation prototypes in the eThekwini Municipal Area (Durban), South Africa. Between 2017 and 2020, 15 sanitation systems were tested in informal settlements, peri-urban households, and other 'real world' settings. This paper illustrates the lessons learned from establishing and managing this testing platform. Costs and timelines for testing are dependent on several factors, including the aims of testing, the development stage of the prototype, whether testing takes place in a community or household setting and if a testing site is shared between prototypes. Timelines were routinely underestimated, particularly for community engagement and commissioning of prototypes to reach steady-state operation. Personnel accounted for more than half of the EFTP's costs. The presence of the municipality as a platform partner was vital to the success of testing, both for gaining political support and for enabling access to testing sites. It is noted that working in communities, with test sites in public spaces, requires technical and social sensitivity to context. It was important to ensure testing supported future municipal decision-making on service provision, as well as longer-term development within communities. The high number of stakeholders, locally and internationally, raised management challenges common to any large project. However, the EFTP added value to TDs, the eThekwini Municipality, and communities requiring improved sanitation services; this was amplified through the platform approach.

\section{INTRODUCTION}

Approximately two billion people, predominantly in developing countries, still lack access to basic sanitation (WHO 2017). Non-sewered sanitation is an important part of the mix of technologies needed to close the sanitation gap globally, provided that technologies are safe, sustainable, affordable, and acceptable to users (Schrecongost et al., 2020).

The launch of the 'Reinvent the Toilet Challenge' by the Bill \& Melinda Gates Foundation in 2011 provided a funded innovation programme for technology developers (TDs) and researchers to identify and design sustainable non-sewered technologies for under-served communities. Based on NASA's new product development (NPD) framework (NASA, 2012), these technologies move through 9 technology readiness levels (TRLs), from laboratory-based initial research and development (TRL 1-3), through technology demonstration in various environments (TRL 4-6), to production and deployment (TRL 7-9) (details in Table A1, Appendix).

In 2017, the Engineering Field Testing Platform (EFTP) funded by the Gates Foundation was established to provide a space in the eThekwini Municipal Area (Durban), South Africa, for TDs to test their prototypes. Early field-testing of prototypes between TRL 5 (laboratory-based prototype demonstration) and TRL 7 (prototype demonstration in an operational environment) in 'real world' settings assists TDs in developing a final product that is safe, practical, sustainable, affordable, and acceptable to users. The EFTP is a unique collaboration between the eThekwini Water and Sanitation unit (EWS) (the municipality), the Water, Sanitation \& Hygiene Research \& Development Centre (WASH R\&D Centre, formerly the Pollution Research Group), and the School of Built Environment and Development Studies (SoBEDS) at the University of KwaZulu-Natal (UKZN), and Khanyisa Projects, a private engineering company. The inclusion of a municipal department as a core partner in the platform differentiated the EFTP from other testing programmes and was critical to its success.

Durban is one of the fastest growing metropolitan areas in South Africa, with a rapidly urbanising peri-urban fringe and the densification of numerous informal communities which are underserved by basic services (Stats SA, 2018). As the water services authority for a water-scarce region, EWS has demonstrated innovation in incremental water and sanitation solutions for under-served communities (Sutherland et al., 2014, Frankson, 2015), but recognises the need for appropriate longer-term solutions. Therefore, EWS is continuously identifying affordable sanitation technologies which require little to no potable water or electricity to operate and which provide a safe and hygienic sanitation service for the end-user.

\section{CORRESPONDENCE}

RC Sindall

EMAIL

rcsindall@gmail.com

\section{DATES}

Received: 10 February 2021

Accepted: 8 October 2021

\section{KEYWORDS}

new product development on-site sanitation

field trials

project management

reinvented toilet

next generation sanitation

\section{COPYRIGHT}

() The Author(s) Published under a Creative Commons Attribution 4.0 International Licence (CC BY 4.0) 
The aim of this paper is to summarise the lessons learned during the implementation of the EFTP, focusing on benefits, challenges and mitigations adopted, including details of timelines and budgets.

\section{METHODS}

Between 2017 and 2020, the EFTP tested 15 prototype sanitation systems across 17 different testing sites: a university laboratory, informal settlement communities, peri-urban households, an office, and a primary school. All work carried out on the EFTP was given ethical clearance by the Biomedical Research Ethics Committee (BREC) and the Humanities and Social Sciences Research Ethics Committee (HSSREC) of the University of KwaZulu-Natal (protocols BE259/19, BE047/19, BE046/19, BE045/19, BE370/18, BE317/18, BE421/18, BE409/17, BE577/17, HSS/0153/019, HSS/0152/019, HSS/2251/017, HSS/1830/017, HSS/1035/017, and exemption EXM/067/018).

\section{Structure of EFTP}

Each EFTP technology follows a series of 6 core steps, shown in Fig. 1. More detail on each of the stages is available in Sindall et al. (2020).

Several role players participated in the EFTP, including TDs, the platform partners (EWS, WASH R\&D Centre, SoBEDS, and Khanyisa Projects), the funder, and the communities where testing took place. A detailed description of the roles of these stakeholders are discussed in Mercer et al. (2018) and summarised in Table A2 (Appendix).

Throughout the EFTP, platform partners met monthly to discuss progress, challenges, and mitigations. Monthly meetings were held with TDs, as a forum for sharing issues affecting the EFTP and lessons learned. The EFTP team met regularly with individual TDs to discuss the testing of specific prototypes. Logs for each prototype were kept, detailing operation and maintenance interventions, design changes, other events impacting the system, and lessons learned. These logs and notes were used to identify recurring challenges and preferred solutions across the platform. They were discussed with all platform team members at a 2-day workshop run by an external facilitator, to understand how the EFTP could be improved in the future or if a similar platform were established elsewhere. The results of this workshop are summarised in this paper as lessons learned.

The documented costs and project timelines for 6 communitybased and 2 household-based prototypes (Table A3, Appendix) were analysed to provide indicative ranges of budget and time requirements for testing prototypes of different types and in different locations. These were standardised to an average 6-month-steady-state testing period (range of 1-18 months), allowing comparison between projects.

\section{RESULTS}

\section{Costs and timelines associated with prototype testing in} eThekwini

Costs and timelines associated with testing varied substantially and were influenced by:

- Number of users (i.e., household or community site)

- Opportunity to share infrastructure if other prototypes were tested at the same site

- Prototype TRL

- Aims of testing

- Time taken to reach a steady operational state after installation

\section{Estimated timelines}

Due to the number of stakeholders involved and limited clarity on which stakeholder had final responsibility for driving the programme, management of timelines was a continual challenge. Table 1 provides an overview of project timelines in relation to three different types of prototypes tested at different site types. Often, testing times were underestimated by both TDs and platform partners. Community engagement was expected to be a major factor in the overall timeline of the project. Delays with technical planning or construction prior to field-testing also resulted in delays, which could impact community perceptions of the project based on existing expectations of service delivery timelines. Ethical approval often took 2 to 3 months, which could delay the start of testing if study designs were not agreed and submitted sufficiently in advance.

Time-savings were observed during concurrent testing, since inhouse personnel and equipment already in place could be used. However, timelines of certain prototypes were extended when decisions had to be taken about which prototype to prioritise during busy periods.

\section{Estimated costs}

Figure 2 indicates projected costs of testing a prototype in Durban for a standardised 6-month steady-state testing period at a single household and a community site. These costs include human resources and all operational costs, except capital and shipping costs, local taxes, and contingency funds. Overheads were included as general and start-up costs or, when personnel related, were built into the daily rates used to calculate human resource (HR) costs. Figure 2 shows that site design and construction and testing incur the largest proportion of the costs of testing a prototype. More details of costs associated with each stage of the project are given in Table A4 (Appendix). HR (project management, engineers, technicians, community engagement specialists and social scientists) accounted for

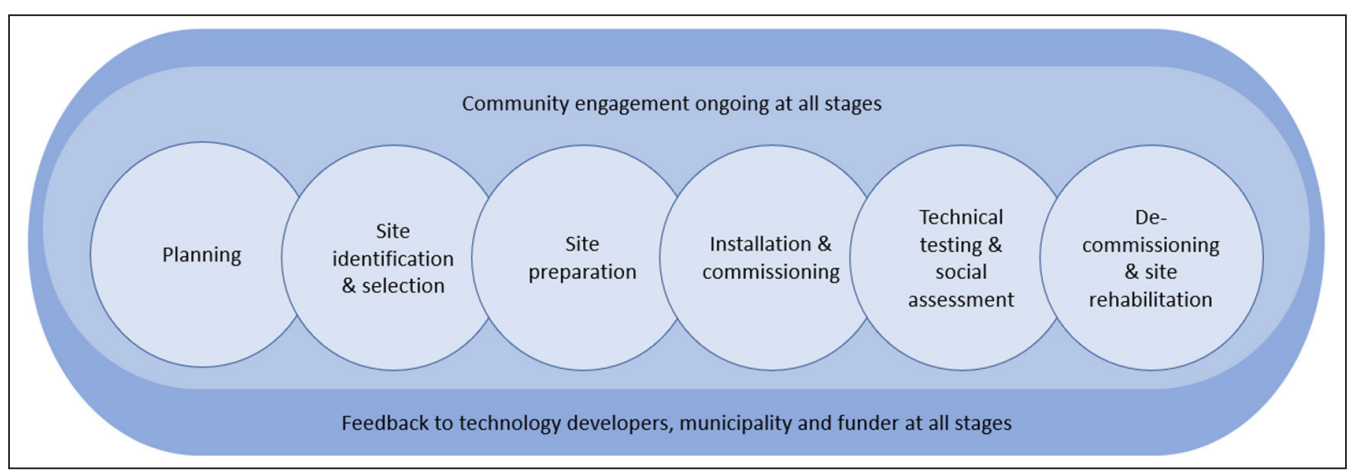

Figure 1. Core steps of the EFTP in Durban, South Africa. NB: Prototype construction and shipping took place before installation but occurred outside South Africa. 
Table 1. Timelines for each project stage in the testing of three prototypes in different locations on the EFTP in Durban

\begin{tabular}{|c|c|c|c|}
\hline Project stage & Pedestal in a household & Back-end system in a community & Integrated system in a school \\
\hline Site identification & 1 week & 3 weeks & 4 weeks \\
\hline $\begin{array}{l}\text { Community } \\
\text { engagement }\end{array}$ & $\begin{array}{l}2 \text { weeks upfront } \\
\text { Ongoing throughout testing }\end{array}$ & $\begin{array}{l}2 \text { months upfront } \\
1 \text { meeting / week (group or individuals) or } \\
\text { as needed throughout testing }\end{array}$ & $\begin{array}{l}6 \text { weeks } \\
1 \text { to } 2 \text { meetings / month with } \\
\text { leadership }\end{array}$ \\
\hline Ethics application & 2 months & 3 months & 3 months \\
\hline $\begin{array}{l}\text { Site design and } \\
\text { preparation }\end{array}$ & 3 weeks & 3 months & 3 months \\
\hline $\begin{array}{l}\text { Installation and } \\
\text { commissioning }\end{array}$ & 1 week per household & $\begin{array}{l}2 \text { weeks (installation) } \\
2 \text { months (commissioning for biological } \\
\text { system) }\end{array}$ & $\begin{array}{l}1 \text { month (installation, including } \\
\text { rectifying compliance issues) } \\
3 \text { months (commissioning for } \\
\text { biological system) }\end{array}$ \\
\hline Testing & $\begin{array}{l}1 \text { to } 3 \text { months per household } \\
\text { (testing in multiple } \\
\text { households consecutively } \\
\text { may be desirable) }\end{array}$ & 12 to 18 months & 18 months \\
\hline Social assessment & $\begin{array}{l}3 \text { days/household (pre-, mid- } \\
\text { and post-surveys) } \\
1 \text { month analysis and write up }\end{array}$ & $\begin{array}{l}3 \text { - } 5 \text { days baseline assessment } \\
1 \text { day interim assessment } \\
2 \text { days final assessment } \\
3 \text { months analysis and write up }\end{array}$ & $\begin{array}{l}1 \text { day per focus group } \\
1 \text { month to write up }\end{array}$ \\
\hline $\begin{array}{l}\text { Decommissioning } \\
\text { (excluding reporting) }\end{array}$ & 1 week per household & $\begin{array}{l}1 \text { month } \\
\text { Additional time to implement appreciation } \\
\text { gesture to community for hosting testing }\end{array}$ & $\begin{array}{l}1 \text { month (decommissioning of } \\
\text { site, rehabilitation) } \\
\text { Additional time to implement } \\
\text { appreciation gesture to school } \\
\text { for hosting testing }\end{array}$ \\
\hline
\end{tabular}

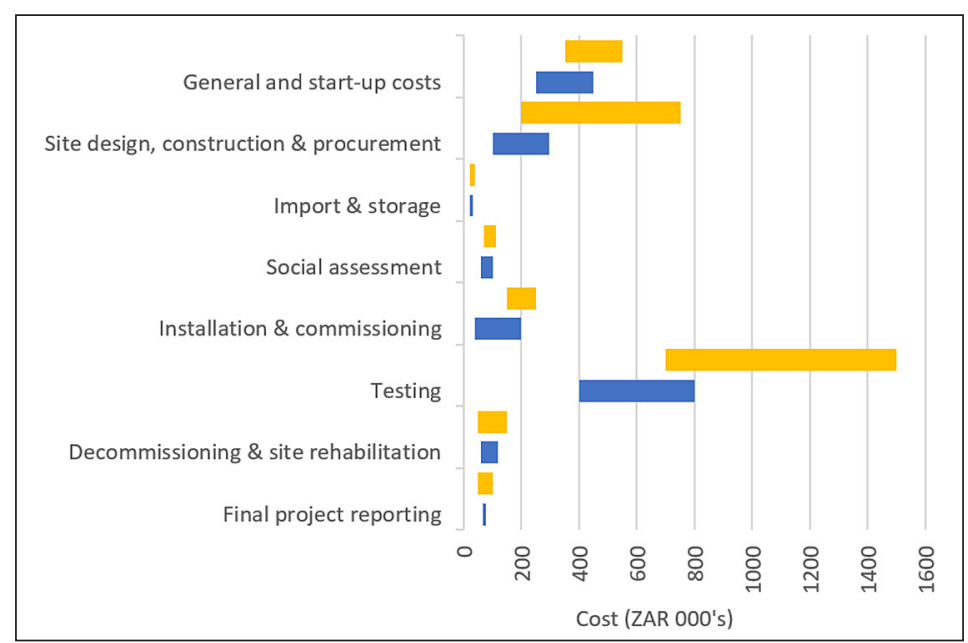

Figure 2. Indicative costs for field-testing a single prototype at steady-state for 6 months in a community (yellow) or household (blue) location. Note that 6 months of steady-state testing results in a project duration of 12-14 months from initiation to completion of final reporting

$50-60 \%$ of costs, with testing incurring a higher proportion of HR costs than site design and construction. Costs do not include in-kind contributions provided by EWS; these included support from a community engagement expert, access to technical staff as required, cross-departmental support such as maintenance of existing services in the community, management contributions to running the platform and facilitating political support, and free use of space at municipal sites for storage and testing. The support from EWS was consistent over time and independent of the number of prototypes being tested. It is difficult to estimate the monetary value of EWS' contribution as no new personnel were employed, but various functions of EWS could not have been replicated by other project partners.

Developing a new community-based testing site and carrying out testing over 6 months at steady-state operation (14-month total project period) for a single multiuser system (no sharing of infrastructure) with a high TRL cost approximately 2.7 million ZAR (177 670 USD, based on an average exchange rate of 15 ZAR $=1$ USD). Testing a single-user system with a high TRL at a new household site, with the same exclusions, cost approximately 1.7 million ZAR (113 333 USD). As prototypes were often tested on the same sites, savings were made by sharing infrastructure and resource costs across multiple prototypes. Thus, testing a multi-user system for 6 months at steady-state operation at an already established testing site shared with other prototypes cost around 2 million ZAR (133 733 USD). During the steady-state testing period, monthly costs were less variable than during the preparation and close-out stages, although these were influenced by factors such as how much the planned laboratory testing varied throughout the test period.

The EFTP operated to support experimentation for prototype optimisation and additional tests were often included as the project progressed and prototypes were modified, which added to overall costs. However, increasing the steady-state testing period by a block of 3 months only increased the total project costs by $10-15 \%$. Hence, longer testing periods were able to provide more extensive performance data for a relatively low additional cost. 


\section{Key lessons learned}

The lessons highlighted focus on the challenges and opportunities at a platform-wide scale, and how these were mitigated or enhanced, and not on technical aspects of specific prototypes.

\section{Lesson 1: Government support is critical to establishing an enabling environment}

eThekwini Municipality was well-placed to host the EFTP. EWS has been open to innovative sanitation solutions since 2000, when alternative solutions to safe and dignified sanitation were needed for nearly a million new residents in unserved peri-urban areas (Gounden et al., 2006; Sutherland et al., 2014). Since then, EWS has developed a close collaboration with the WASH R\&D Centre as a sanitation research partner. This internationally recognised partnership, with its appetite and support for innovation, was key in selecting Durban for the EFTP. Furthermore, the WASH R\&D Centre has a well-equipped laboratory experienced in handling faecal sludge, and a well-developed research relationship with social scientists in SoBEDS. Khanyisa Projects, a small engineering company, was identified as a necessary third partner. They were able to quickly implement solutions on the ground when internal processes at the university or municipality would have slowed work down. Government support and institutional arrangements, two of the six elements of an enabling environment for Community-Led Urban Environmental Sanitation (CLUES) (Lüthi et al., 2011) were therefore present in Durban.

Having EWS as a core team member allowed access to sites, both via their role as the water services authority and as part of the municipality. EWS provided in-depth knowledge of the existing water and sanitation infrastructure, and access to a skilled, experienced community engagement team who provided a detailed understanding of the community and political context of identified sites. As respected and trusted community liaison officers, they added legitimacy to the project, playing a vital role in introducing the EFTP to communities where testing could take place, liaising with community members and leadership to secure approval for testing, and addressing issues raised by the community and the EFTP team throughout the project. Working with communities that had previously participated in communitybased research often meant that people were more receptive to the EFTP (Sutherland et al., 2021a), though occasionally communities were wary of what was perceived as continual research without real change. EWS was also able to secure highlevel political support through meetings with councillors, and facilitated communication with other municipal departments as required, e.g., liaising with the electricity department to connect prototypes to mains power. Without this enabling environment, project timelines would have been extended due to the additional challenges of identifying and securing approval to access testing sites, project shutdowns by communities who felt excluded, and delays for the provision of critical infrastructure.

Other aspects of this environment had to be developed. At the inception of the EFTP, no South African regulations existed for the quality of recycled water for toilet flushing, a goal of many of the prototypes. Thus, a water recycling standard was developed by the WASH R\&D Centre in consultation with EWS, considering national standards from other countries (BS:8525-2:2011; USEPA, 2004; NSF/ANSI:350, 2017a) and the local context, e.g., recycled water must be safe for human contact since small children play with water in communal toilet blocks.

\section{Lesson 2: Technologies must be localised to suit the testing environment}

TDs had different goals for testing on the EFTP. Some had an interest in the applicability of their prototype for the South
African market whilst others wanted 'real world' testing results for their prototype in a wider market. Regardless of the aims, appropriateness for the South African context had to be considered. EWS was given authority to request changes to, or to decline, the testing of any prototype deemed inappropriate due to societal, political, or technical reasons. For example, the historical context of the bucket-toilet system and its links to apartheid means that container-based sanitation systems are a politically sensitive technology within South Africa. The most frequently encountered reasons for prototypes requiring a degree of localisation are discussed below.

South African regulations are often more stringent than international requirements (e.g., discharge effluent quality compared to ISO30500 (ISO, 2018)). Effluent quality for environmental discharge and electrical compliance were considered in advance to ensure that local requirements were met. If a prototype could not be modified to meet local regulations, it was not tested in South Africa.

South Africans are 'sitters' and 'wipers' and use toilet paper or other anal-cleansing materials (e.g., newspaper) which is disposed of in the toilet bowl. Prototypes needed to handle these solids in addition to faecal material, which posed challenges for prototypes designed for, or previously tested in, 'washer' environments that use water for anal cleansing. Multiple prototypes included components requiring regular maintenance to prevent toilet paper wrapping around moving parts or causing blockages as it dried and solidified in tanks or pipes. Moreover, the high fat content in many South African diets leads to scum formation (Srivastava, 2018) which impacted the operation and maintenance schedules of prototypes. It is recommended that TDs consider how their sanitation technologies will deal with 6 elements in input streams: faeces, urine, flush water, paper, scum (particularly in holding tanks) and foreign objects (e.g. menstrual hygiene products, rags, toys).

Security and preventing vandalism were a concern when placing high-value systems in some communities, and TDs were encouraged to incorporate security measures into the system design where possible, to avoid retrofitting these features on-site. The requirements for such measures were dependent on the testing site. At informal community sites, theft was relatively low where there was a cohesive community, continuous engagement between the project team and the community, and hence a sense of community ownership of the site, the testing process and prototype (Sutherland et al., 2021a). In the school setting, fencing, an alarm system, and a security guard were required to minimise theft and vandalism from persons outside the school environment. Household testing sites were often lowest risk, as there was strong ownership of the prototype and an interest in making testing a success (Sutherland et al., 2021b).

From a technical perspective, availability of spare parts is important for continued operation and preventing delays to maintenance. Thus, the local availability of suitable parts (either off-the-shelf or custom-manufactured) must be considered so that procurement of critical spare parts can be planned well in advance. Climate can impact on the durability and rate of corrosion of some components, and the high humidity in Durban resulted in shorter lifespans than expected for some metal or rubber components.

Finally, even when sites with access to water and electricity were selected, power and water outages were common, and contingency planning to accommodate these were vital for prototypes reliant on these services.

\section{Lesson 3: Continuous community engagement is vital to ensure social justice, address concerns, and foster participation}

South Africa is a participatory democracy; hence community engagement led by EWS, and supported by social scientists from 
other platform partners, was a crucial element of prototype testing. The municipality has a good understanding of the context and socio-political dynamics of communities within their jurisdiction and any work related to sanitation reflects on them as the service provider. Socio-political factors were found to have greater impact on the selection of suitable testing sites than engineering factors, as without community acceptance of the project and permission for testing, no work could take place, even if the site was technically well-suited to the prototype. The involvement of EWS was critical for site selection and ensuring that relevant permissions were granted from all leadership structures. These included ward councillors, traditional authority leadership, proportional representation councillors (who represent opposition political parties), and community leadership committees. Social scientists from SoBEDS provided input into site selection based on their understanding of the sociotechnical and political relations of sanitation in Durban. This process is time-consuming, and as the formal and informal power structures in communities are dynamic, continuous engagement between platform and community was required to ensure that issues arising were appropriately addressed.

Community expectations, including employment opportunities, the ability to solve issues beyond the scope of the EFTP (e.g., housing or electrical connections), and the duration of the prototype on site had to be managed during community engagement. Unemployment is high across South Africa (reported by StatsSA (2019) as 27.6\% for the first quarter of 2019), so trade-offs were made between community needs for jobs and project timelines, such as employing local manual labour for excavation rather than using machinery despite the additional time required. Creating work opportunities, such as community liaison officer (CLO) positions at testing sites, also allowed for skill development. One CLO showed great interest in the operation of the community prototypes so the engineers developed his skills as an assistant technician.

Publicity relating to the EFTP was carefully monitored as uncontrolled media exposure puts an increased burden on the community, beyond the ways in which they have agreed to help. It also had the potential to impact the way the community viewed the EFTP and their involvement in it, either by increasing expectations of the value testing can bring to communities, or by putting them in a situation where they feel they are being exploited.

Communication during site selection was paramount, necessitating clear explanations to the community engagement team why one site was selected over another, so they could share this information with others. Selection criteria included site access requirements, number of permanent residents, and existing security, e.g., fencing. Even so, social acceptance studies revealed some complaints from neighbours who were not part of a testing opportunity, and which had created tensions during the testing period.

Community members, including CLOs, acted as an important safety net for EFTP personnel working at the site, as well as preventing vandalism and theft. Two-way communication between the EFTP and the community was integral; members could ask questions, raise concerns and feel that these were taken seriously. If the community reported leaks or overflows, these would be dealt with promptly and effectively. Similarly, it was important that the EFTP team provided regular feedback on testing progress, delays, and issues. When communities were proactive in identifying and clearing testing spaces for prototypes, they expected a similar rate of progress for site preparation and installation. For example, shipping delays could negatively impact community support if they were not fully explained. The responsibility for this two-way communication lay with the community engagement team and other EFTP team members who spent time on site. Prototype engineers became an integral part of engaging with communities, particularly at household sites where they were the primary route for informal engagement between householders and the EFTP team.

Users were instructed how to use prototypes if deviations to usual behaviour were expected, and reminded if there were signs that behaviours were reverting to pre-testing norms. Two prototypes were not compatible with the cleaning product used at communal toilets so caretakers were shown how to use new cleaning chemicals supplied by the EFTP. On another prototype, greywater disposal to urinals caused dilution of the urine feed to the system, resulting in poor process performance. A community-wide intervention was included as part of a public holiday celebration, explaining why greywater should not be put down urinals and where it should be disposed of. Disposal of greywater into urinals was minimal following this intervention.

For communities, sanitation is part of a wider community development agenda, and involvement in the EFTP had larger implications for interaction with local governance structures. Since councillors took an interest in the EFTP and attended EFTP meetings at sites, this allowed communities greater access to councillors than usual. Similarly, the close collaboration with the municipality meant that issues with municipal infrastructure in host communities were likely to be dealt with promptly. The community was able to leverage the EFTP to reduce the distance between themselves and formal support structures in the municipality, as well as to access development support through other stakeholders (Sutherland et al., 2021a; 2021b). This was evident when two informal settlement sites experienced disasters (flooding and fire) during the testing period and the EFTP was able to mobilise charitable donations to provide disaster relief support. On other occasions, UKZN and Khanyisa Projects hosted educational events for school-age learners and career information events for unemployed youth as part of giving back to the community. It is important to note that this exceptionalism of rapid response to sanitation issues and community support may be represented as an unduly positive response to the acceptability of prototypes if data is not carefully analysed by a team with experience of local context and comprehension of testing within the wider platform.

At the end of the testing period, proposed site improvements were identified in consultation with the community and changes implemented as a gesture of appreciation for their involvement. These included emptying existing urine diversion toilets at households, fixing existing toilet blocks at schools, and installing communal infrastructure such as play parks or washing lines.

\section{Lesson 4: Testing prototypes in non-ideal spaces come with technical challenges}

Establishing and running prototype testing sites in spaces where people live and work carries multiple technical and safety challenges. Design of site infrastructure was normally carried out in the absence of as-built drawings or information on existing infrastructure. Also, illegal electricity and water connections were common, particularly at informal settlement sites. Illegal electricity connections were often bare cables running at, or just below, ground level and posed serious safety risks to construction personnel. Underground services detection was carried out at community sites during the design phase to minimise the risk of hitting cables and water pipes.

Other challenges included steep terrain and unfavourable ground conditions for excavation, restricted road access for transporting prototypes to site, and limited space subject to multiple uses, including laundry and play areas, gardens, and small businesses close to existing toilet blocks. These factors made site design 
and preparation challenging. It was therefore valuable for TDs to incorporate as much flexibility into their design as possible to avoid dependency on specific site configurations. Adjustableheight inlet positions on tanks meant that the length of a gravity flow pipe feeding the tank, and thus the position of a tank on site, could be varied. Rotating solar-panels negated the need for a prototype to be orientated in a specific direction. Working space for engineers and secure storage were incorporated on site where possible, but in extreme heat these could become very hot, meaning temperature-sensitive equipment such as batteries required special arrangements.

During site design, provision was made for out-of-specification effluent or emergency conditions, when effluent had to be diverted to waste rather than its intended end use (e.g., toilet flushing). Where possible, diverts to sewer were installed or emergency tank storage was provided. The inclusion of remote monitoring and alarm systems were valuable in the case of system malfunctions, but their feasibility could be limited by mobile phone coverage.

The unknowns associated with community sites meant that design engineers and contractors had to prepare for unexpected issues and on-the-job problem-solving during construction. Small local contractors were used for construction work to support the communities' requests for the project to contribute to the local economy. Some tasks were outside the contractors expertise, requiring increased input and supervision from EFTP staff. Similarly, significant site supervision was required during construction to ensure activities were carried out safely (e.g., the management of deep excavations), especially in cases where there was little room for deviation from design (e.g., correct fall on a gravity pipeline). Budgets and timelines for site preparation had to account for all these elements.

Due to limited space and close interactions between community members and the prototypes during construction and testing the health and safety of workers and the public posed significant challenges. It was vital that public liability insurance covered all aspects of installation and testing at sites accessible by the public. For the EFTP, some TDs temporarily donated their prototypes to EWS, or community sites were designated as satellite sites of UKZN. Thus, the municipality or university respectively covered public liability insurance.

Minor theft and vandalism to prototypes were experienced at some sites. Theft and damage insurance was the responsibility of individual TDs, though most chose not to take out insurance. In practice, the EFTP reserved funding for minor loss and damage rather than delaying testing whilst waiting for insurance pay-outs.

Prior to installation, each local system engineer received detailed training, which helped to identify health and safety issues and associated mitigation measures related to operation and maintenance. Likewise, advance training offered an opportunity to provide feedback to the TD on potential design issues specific to the testing context, and to support the development of contextappropriate standard operating procedures. One TD involved the prototype engineer in the construction and pre-shipping tests of the unit to be field-tested, providing the engineer with an indepth understanding of all aspects of the prototype's design and functionality.

\section{Lesson 5: For maximum benefit, testing must be integrated into long-term planning}

Testing needed to provide information that was useful for all stakeholders. As well as technical and social data the TD obtained from testing their prototype, data collected were useful to inform eThekwini Municipality's future decision-making and policies around non-sewered sanitation. Data on grid power consumption, maintenance events, use of chemicals and other consumables, and the personnel time required to operate and maintain systems, was collected across all prototypes to inform municipal decisionmaking on their applicability.

Long-term planning also covered the removal of the system at the end of testing, and a strategy was devised from the time a site was selected, with due consideration given to the implications of non-performance (exit strategies are summarised in Table A3, Appendix). The exit strategy considered whether leaving 'legacy' systems in place was a burden on the community or municipality, who would have to operate and maintain the prototype if it was to remain functional. EWS, in common with most municipalities, do not have the internal processes or staff to maintain oneoff sanitation systems and therefore prototypes were normally removed at the end of testing. This prevented communities being left without access to services, which would have reflected poorly on the TD, eThekwini Municipality, and the EFTP.

Managing decommissioning was challenging, from both social and technical perspectives. For frontend prototypes in households, the prototype was usually far more desirable than the original toilet, so removal of the prototype had to be handled sensitively, as households were disappointed to lose their improved sanitation (Sutherland et al., 2021a). Decommissioning could also involve major construction work on site (e.g., removing large underground tanks and rehabilitating the area) and thus sufficient time and funding must be allocated during planning.

\section{Lesson 6: Upfront agreements and guidelines can help diverse stakeholders to work together}

The TDs involved in the EFTP were not based in South Africa and prototypes had to be shipped into the country for testing. Timelines had to account both for shipping and the time needed to clear customs in South Africa.

Where English was not the working language of the TD, translators with technical language skills (and ideally some technical knowledge) were vital to ensure smooth planning and implementation. Unless the TD intended to have staff on-site throughout the project (which was costly), standard operating procedures needed to be clearly documented in English and a local operator trained to operate and maintain the prototype.

To ensure the EFTP team were providing consistent information and support to communities involved, TDs were requested not to engage directly with community members. As responses to social acceptance surveys are impacted by the history of sanitation provision and the sociopolitical dynamics of communities, social assessments were designed, administered, and analysed by a South African team with significant expertise in this area of research (SoBEDS). Similarly, suggestions and recommendations made by international stakeholders had to be considered within the local context. For example, females were proposed as CLOs to address gender inequality. Whilst in principle this idea had merit, in practice the community leadership had the final say and leadership deemed this approach to be infeasible. Rejecting this guidance may have risked losing community support for the project. A separate research project investigating how sanitation testing can be better utilised to address gender equity is underway.

The diversity of stakeholders associated with the EFTP meant that ownership of data had to be clarified, together with guidelines for its publication. As many of the TDs are university researchers, journal papers and conference presentations were important forms of data sharing from the EFTP. It was necessary to provide clear guidance on who should be considered as authors or acknowledged on papers, to prevent researchers' contributions being overlooked or underemphasised. 
Working with international partners and funders over a 3-year period meant that changes in exchange rates had both positive and negative impacts on budgets at different points in the programme. The volatility of exchange rates was factored into project planning and it was beneficial to report to the funder both the positive and negative deviance from budget due to exchange rates, so that budgetary changes were transparent.

\section{Lesson 7: Collaborative management is challenging but can deliver remarkable flexibility}

As with any large international project, certain accepted project management challenges were experienced. Clear roles and responsibilities must be agreed with the stakeholders for each stage of the project, and different approaches were taken for each prototype based on the goals of the testing and the organisational characteristics of the key stakeholders involved. In some cases, the responsibility for driving the project (between the EFTP team, the TD, and the funder) was unclear, which had an impact on project timelines. Where possible, the responsible partner was identified based on the stage of the project, but at points where decision-making straddled project stages, greater clarity would have been valuable.

Within the EFTP team there were strengths and challenges associated with the model of managing the platform. The collaborative management model adopted by the three Durbanbased partners allowed for flexible decision-making in the face of a highly dynamic programme. This collaborative model functioned well due to the personalities involved, and the existing relationships and shared history of previous projects between the organisations and individuals concerned. The shared trust between team members built in accountability for achieving results without the need for a hierarchical management structure. Challenges included management of timelines and defining divisions of responsibilities.

To identify roles and responsibilities, clearly stated project goals for testing each prototype should be documented before the project starts, to reduce scope creep and inevitable impacts on budget and timeline. Finally, the co-ordination of numerous stakeholders carrying out a wide range of activities, often on tight timelines, required significant dedicated staff time from the EFTP management team.

\section{DISCUSSION}

The value of the EFTP is categorised based on which stakeholders benefited.

\section{Changes to design based on feedback}

User and operator feedback on the prototype allowed TDs to identify and implement design changes for both the global and South African context. For example, when testing a dry-flush pedestal at multiple household sites, concerns were raised by users that the pedestal bowl did not stay clean, and they felt they were sitting very close to their waste. Thus, the TD increased the depth of the bowl so waste was further away from the user, integrated an automatic lubricant spray into the bowl before use to prevent faeces sticking, increased the size of the dry swipe used to "flush" the toilet to reduce smearing, and changed the material of the bowl to reduce fouling.

Similarly, feedback from the prototype engineer regarding the ergonomics and frequency of certain maintenance tasks, such as nutrient capture bed regeneration, for a membrane bioreactor and nutrient capture treatment process, resulted in the TD adapting later designs to improve access to certain valves and tanks.

Not all feedback to TDs came from the testing stage. The process of installing a prototype in limited space at a community site resulted in several recommendations. These included: splitting the prototype into two units to reduce the truck size required to transport the container to site (and therefore the size of the access roads), allowing the rooftop solar assembly to rotate so that the prototype did not have to face a specific direction, and making all toilet waste pipes accessible so that blockages could be easily resolved.

\section{Interest in prototypes from commercialisation partners}

An important advantage of the EFTP was that it offered a showcase of prototypes that were operational in the environments where they are intended to be used. This provided a greater level of confidence to potential commercialisation partners than operation in a controlled laboratory setting. In 2017, the South African Government, in partnership with the Gates Foundation, launched the South African Technology Sanitation Enterprise Programme (SASTEP), which aimed to support the commercialisation of promising sanitation technologies. This initiative provides a platform where local commercial partners and entrepreneurs can collaborate with TDs and other partners to drive the new sanitation market in South Africa. At least one of the technologies tested in the EFTP was included in SASTEP. The knowledge and data collected during the EFTP was used to demonstrate to commercial partners that the prototype was suitable for the South African market.

\section{Value to the municipality}

Multiple benefits relating to sanitation service provision were identified by EWS. The most apparent of these was exposure to innovative sanitation technologies in the early stages of development that might prove applicable to the Durban context, and the opportunity to have input into its development for use in that context. Having local knowledge of the operation and performance of these systems, and feedback on acceptability from intended end-users, helps give confidence that the systems are fit for deployment in the municipality. Through collaboration with the EFTP team, municipal operations and maintenance staff were able to identify how the sanitation technologies could fit within the existing sanitation service provision framework and gained uptodate knowledge of innovative non-sewered sanitation. However, the TRL of the prototypes tested had an impact on the value of this exposure. It was often frustrating for municipal engineers that systems with lower TRLs were being tested and were not at a stage where they could be quickly rolled out to underserved communities or schools if they were shown to perform well.

The municipality received detailed insight into social acceptance of sanitation systems and the needs of communities, and how service provision connects to other aspects of community development. For example, the Human Settlements Unit, through its iQhaza Lethu informal settlement upgrading programme, has an interest in identifying sanitation technologies that can be integrated into informal settlement upgrades. On-site or decentralised treatment options offering alternatives to centralised treatment works are of great interest to the Development Planning, Environment and Management Unit. In addition, the Research and Policy Advocacy Unit have shown an interest in using the EFTP as a case study of how to integrate knowledge generated through research into municipal policy. The collaborative and transdisciplinary approach of the EFTP allowed the municipality to collaborate with a wide range of stakeholders to gain a broader perspective of sanitation needs, and the potential for non-sewered sanitation to meet those needs.

\section{Value of the platform approach}

The EFTP tested multiple technologies at many testing sites, which allowed for the costs of personnel and facilities to be shared and 
overall costs reduced. Where infrastructure could be reused, the timelines associated with site preparation were reduced, and in all cases where sites were reused, the additional time associated with community engagement was minimised. Institutional memory was retained as dedicated and specialist staff were employed and their time shared across multiple prototypes, rather than having to introduce expertise for individual prototypes. One of the challenges of this approach is that changes to timelines for one prototype can easily impact on other prototypes when resources are shared.

The platform approach also offered opportunities to external stakeholders with an interest in multiple sanitation technologies. It allowed visitors to view and understand a wide range of sanitation technologies in a single location, and visits were held with provincial and national government officials, representatives of municipalities from across Africa, and potential commercialisation partners. The platform also offered TUVSUD (a global testing, certification, inspection, and training services provider) the opportunity to test the ISO30500 standard (ISO, 2018) to identify the organisational requirements and costs associated with testing and certifying nonsewered sanitation technologies against the standard. While not the main purpose of the platform, these activities provide an opportunity for education and advocacy on the benefits of innovative non-sewered sanitation and contribute to the wider development and acceptance of nonsewered sanitation.

\section{Reproducibility of the EFTP}

The EFTP was funded by a single donor. Figure 2 shows that 6 months of steady-state testing costs approximately 1.7 million ZAR for a household testing site and 2.7 million ZAR for a community testing site. Without donor-supported funding, fieldtesting would most likely require private sector backing; thus, the business case relating to the available market and future profit potential must be made clear. This is challenging until field-testing is complete. Alternatively, the public sector could incentivise TDs to field-test as a route towards technology adoption. Again, the public sector needs to see the feasibility of new sanitation technologies to fill existing service delivery gaps.

The programmatic funding of a platform, rather than projectbased funding for individual prototypes, allowed for greater staff retention and consequent building of experience and learning, and reduced the costs of testing for each prototype.

Whilst existing partnerships and government support of innovation in Durban laid a valuable foundation for the EFTP, it would be possible to set-up smaller scale testing platforms in other locations. To achieve this, the importance of the enabling environment must be understood, and the necessary effort made to capitalise on existing partnerships and build-in the factors missing from that environment.

It was clear from experiences where prototypes had previously been tested in 'washer' rather than 'wiper' communities that these distinctions must be carefully considered, as the results of testing a system in a 'wiper/sitter' community are not easily translated to 'washer/squatter' communities and vice versa. However, there are aspects of the EFTP that would translate well to other urban informal settlement settings or to similar peri-urban household settings. As such, it is suggested that field-testing can be viewed as having regional relevance, with results from Durban being applicable within sub-Saharan Africa and other testing platforms in similar contexts.

\section{CONCLUSION}

The experience of the EFTP in Durban demonstrated that early field-testing of prototypes is beneficial for identifying and mitigating process, component, and user preference issues prior to commercialisation. In this way, the final product is suitable for the local environment and climate, as well as the sanitation practices and social context of the intended end-users.

The implementation of the EFTP in a single municipal area has allowed for resource sharing and cost reduction by using sites to test multiple prototypes and share the expertise and knowledge of a dedicated team.

Existing partnerships and an appetite for sanitation innovation in EWS provided a vital enabling environment for the EFTP. Localisation of prototypes to the South African context is necessary for testing to run smoothly, and making adaptations in advance or allowing for flexibility in prototype design will reduce the costs associated with localisation.

Running innovative sanitation systems that are still in the development stages in communities comes with multiple social and technical challenges and opportunities. Open, transparent, and continuous community engagement is vital for the success of field-testing and requires commitment to respectful coproduction of knowledge. The value of the EFTP to the community has the potential to be significantly greater than simply access to improved sanitation, and whilst that is recognised by the EFTP, participatory processes need to be agreed by all stakeholders and carefully managed. From a technical standpoint, working in communities offers several challenges relating to unpredictable conditions, which require that the health and safety of workers and the public are carefully considered.

The EFTP has shown it offers value to TDs who are able to update designs based on social acceptability feedback, to the municipality who gain early exposure to relevant tested sanitation technologies, and to the sanitation sector in South Africa and the global south, as an early 'real world' test of innovative, non-sewered sanitation systems prior to commercialisation.

\section{ACKNOWLEDGEMENTS}

The authors would like to acknowledge the Bill \& Melinda Gates Foundation for funding this research (grant number OPP1170678), the eThekwini Municipality (Water and Sanitation Unit) for providing on-the-ground support, and the communities who participated in the EFTP and co-produced knowledge with us.

\section{AUTHOR CONTRIBUTIONS}

RC Sindall - conceptualisation, methodology, investigation, writing (original draft; review and editing), supervision, project administration; R Cottingham - conceptualisation, methodology, investigation, writing (original draft; review and editing), supervision, project administration; $\mathrm{P}$ Arumugam - writing (original draft; review and editing); SJ Mercer conceptualisation, methodology, investigation, writing (review and editing), supervision, project administration; C Sutherland - conceptualisation, methodology, investigation, writing (review and editing), supervision, project administration; N Alcock conceptualisation, writing (review and editing), supervision, project administration, funding acquisition; CA Buckley conceptualisation, resources, writing (review and editing), supervision, funding acquisition; G Gounden - conceptualisation, resources, writing (review and editing), supervision, funding acquisition.

\section{REFERENCES}

BS:8525-2:2011 British Standard Greywater Systems. Domestic Greywater Treatment Equipment. Requirements and Test Methods. BSI Publications, London. ISBN 9780580634765. 
USEPA (United States Environmental Protection Agency) (2004) National Recommended Water Quality Criteria. USEPA, Washington D.C.

FRANKSON L (2015) eThekwini scoops award for innovative sanitation solution. Infrastructure News. https://infrastructurenews. co.za/2015/05/19/ethekwini-scoops-award-for-innovative-sanitationsolution/ (Accessed 25 June 2020).

GOUNDEN T, PFAFF B, MACLEOD N and BUCKLEY C (2006) Provision of free sustainable basic sanitation: the Durban experience. In: $32^{\text {nd }}$ WEDC International Conference: Sustainable Development of Water Resources, Water Supply and Environmental Sanitation, 13-17 September 2006, Colombo. 4 pp.

ISO (2018) International Organization for Standardization ISO 30500 Non-sewered sanitation systems - Prefabricated integrated treatment units - General safety and performance requirements for design and testing. International Organization for Standardization, Geneva.

LÜTHI C, MOREL A, TILLEY E and ULRICH L (2011) Community-Led Urban Environmental Sanitation Planning (CLUES). Swiss Federa Institute of Aquatic Science and Technology (Eawag), Dubendorf.

MERCER SJ, SINDALL R, COTTINGHAM RS, BUCKLEY C, ALCOCK N, ZUMA L and GOUNDEN G (2018) Implementing an engineering field testing platform for sustainable non-sewered sanitation prototypes. $41^{\text {st }}$ WEDC International Conference, Egerton University, Nakuru, Kenya, 2018. URL: https://wedc-knowledge. lboro.ac.uk/details.html?id=22987

NASA (2012) Technology Readiness Level. URL: https://www.nasa gov/directorates/heo/scan/engineering/technology/txt_accordion1. html (Accessed 25 June 2020).

NSF/ANSI:350 (2017a) NSF International Standard/American National Standard for Wastewater Technology: Onsite residential and commercial water reuse treatment systems. American National Standards Institute, Washington D.C.

SHRECONGOST A, PEDI D, ROSENBOOM JW, SHRESTHA R and BAN R (2020) Citywide inclusive sanitation: a public service approach for reaching the urban sanitation SDGs. Front. Environ. Sci. 8 (19). https://doi.org/10.3389/fenvs.2020.00019
SINDALL RC, COTTINGHAM RS, SUTHERLAND C, MERCER S, POCOCK J, ARUMUGAM-NANOOLAL P, DHLAMINI S, MAGWAZA F, SHOZI M, ODILI A and REDDY M (2020) SASTEP Field-testing and demonstration guidelines (version 1; not peer reviewed). Gates Open Res 2021567 (document) https://doi. org/10.21955/gatesopenres.1116768.1

SRIVASTAVA S (2018) Management of scum (fat, oil and grease) in wastewater pump stations: a case study of the eThekwini Municipality, South Africa. PhD thesis, University of KwaZuluNatal.

STATS SA (Statistics South Africa) (2018) General household survey P0318. Statistics South Africa, Pretoria.

STATS SA (Statistics South Africa) (2019) Statistics South Africa P0211 Quarterly Labour Force Survey Quarter 1: 2019. Statistics South Africa, Pretoria.

SUTHERLAND C, REYNAERT E, DHLAMINI S, MAGWAZA F, LIENERT J, RIECHMANN ME, BUTHELEZI S, KHUMALO D, MORGENROTH E, UDERT KM and SINDALL RC (2021a) Socio-technical analysis of a sanitation innovation in a peri-urban household in Durban, South Africa. Sci. Total Environ. 755 a143284. https://doi.org/10.1016/j.scitotenv.2020.143284

SUTHERLAND C, REYNAERT, E, SINDALL RC, RIECHMANN ME, MAGWAZA F, LIENERT J, BUTHELEZI S, KHUMALO D, DHLAMINI S, MORGENROTH E and UDERT KM (2021b) Innovation for improved hand hygiene: Field testing the Autarky handwashing station in collaboration with informal settlement residents in Durban, South Africa. Sci. Total Environ. 796149024. https://doi.org/10.1016/j.scitotenv.2021.149024.

SUTHERLAND C, HORDIJK M, LEWIS B, MEYER C and BUTHELEZI B (2014) Water and sanitation delivery in eThekwini Municipality: a spatially differentiated approach, Environ. Urbanisation. 26 (2) 469-488. https://doi.org/10.1177/0956247814544871

WHO (2017) Factsheet on sanitation. URL: https:/www.who.int/en/ news-room/fact-sheets/detail/sanitation (Accessed 12 May 2020) 
Table A1. The new product development framework adopted by the Bill \& Melinda Gates Foundation for development of non-sewered sanitation

\begin{tabular}{lcl}
\hline Stage & Level & Definition \\
\hline Research and Development & 1 & Basic principles observed and reported \\
& 2 & Technology concept and/or application formulated \\
& 3 & Analytical and experimental critical function and/or characteristic proof-of-concept \\
\hline Technology Demonstration & 4 & Component validation in laboratory environment \\
& 5 & System/subsystem model or prototype demonstration in a laboratory environment \\
& 6 & System/subsystem model or prototype demonstration in a relevant environment \\
\hline Production and Deployment & 7 & System prototype demonstration in an operational environment \\
& 8 & Actual system completed and qualified through test and demonstration \\
& 9 & Actual system proven through successful product launch \\
\hline
\end{tabular}

Table A2. Role players in the Engineering Field Testing Platform (adapted from Mercer et al., 2018)

\begin{tabular}{|c|c|c|}
\hline & How I benefit & What I offer \\
\hline $\begin{array}{l}\text { As a technology } \\
\text { developer }\end{array}$ & $\begin{array}{l}\text { - Space and support to test systems in a 'real world' } \\
\text { environment } \\
\text { - Feedback on prototype designs from users } \\
\text { - Feedback on operation and maintenance } \\
\text { - Generation of performance data } \\
\text { - Identification of areas for improvement } \\
\text { - Opportunities to work with other technology } \\
\text { developers (hybrid systems and shared } \\
\text { infrastructure) }\end{array}$ & $\begin{array}{l}\text { - Sanitation prototypes } \\
\text { - Existing performance data } \\
\text { - Technical expertise }\end{array}$ \\
\hline $\begin{array}{l}\text { As a municipality or } \\
\text { regulator }\end{array}$ & $\begin{array}{l}\text { Early exposure to emerging technology, tested } \\
\text { under local conditions } \\
\text { - Safely managed and customer-tested sanitation } \\
\text { solutions for underserved communities } \\
\text { - Exposure to potential partnerships }\end{array}$ & $\begin{array}{l}\text { - Access to testing sites } \\
\text { - Existing community engagement systems } \\
\text { - Management and technical support to platform } \\
\text { - Testing resources such as storage sites, seed sludge, } \\
\text { water tankers } \\
\text { - Supportive ethos of innovation }\end{array}$ \\
\hline $\begin{array}{l}\text { As a community } \\
\text { user }\end{array}$ & $\begin{array}{l}\text { Safely managed and desirable sanitation solutions } \\
\text { - Job opportunities including skills building } \\
\text { - Heightened profile of community with decision- } \\
\text { makers }\end{array}$ & $\begin{array}{l}\text { - Feedback on prototypes } \\
\text { - Access to communal spaces } \\
\text { - Local labour }\end{array}$ \\
\hline As a platform & $\begin{array}{l}\text { - Income } \\
\text { - Collaborations } \\
\text { - Increased knowledge and ability to offer similar } \\
\text { services }\end{array}$ & $\begin{array}{l}\text { - Existing relationship with municipality } \\
\text { - Technical and social research expertise } \\
\text { - Personnel dedicated to supporting all aspects of testing } \\
\text { - Faecal sludge laboratory }\end{array}$ \\
\hline As a funder & $\begin{array}{l}\text { - Rapid development and commercialisation of } \\
\text { sanitation technologies }\end{array}$ & $\begin{array}{ll}\text { - } & \text { Funding } \\
\text { - } & \text { Long-term vision }\end{array}$ \\
\hline
\end{tabular}

Table A3. Anonymised summary of prototypes tested on Engineering Field Testing Platform

\begin{tabular}{lcccl}
\hline No. & System type & Testing location & $\begin{array}{c}\text { Steady-state } \\
\text { test duration }\end{array}$ & Exit strategy \\
\hline 1 & Pedestal & Household & 6 months & Removed; original toilet emptied and reinstalled \\
2 & Treatment only & Community & 6 months & Removed; toilets reconnected to sewer \\
3 & Integrated & Household & 3 months & Removed; original toilet emptied and painted \\
4 & Handwashing station & Community & 3 months & Removed; nothing installed to replace it \\
5 & Integrated & Community & 6 months & Treatment process removed, toilet block left in place \\
& & School & 9 months & and connected to sewer \\
6 & Pedestal & Laboratory & 3 months & Removed from temporary testing location \\
7 & Pedestal & Offices & 2 months & Removed; original toilet reinstalled \\
8 & Dewatering component & Laboratory & 6 months & Removed; returned to technology developer \\
9 & Drying component & Wastewater treatment works & 12 months & Removed to different testing location for further research \\
10 & Treatment only & Community & 18 months & \\
11 & Treatment only & Community & 6 months & \\
12 & Partial treatment only & Community & 5 months & Removed; toilets reconnected to sewer \\
13 & Pedestal & Laboratory & 3 months & Removed from temporary testing location \\
14 & Separation component & Laboratory & 1 month & Removed from temporary testing location \\
& & Community & 1 month & Removed; toilet reconnected to sewer \\
15 & Partial treatment only & Laboratory & 5 months & Removed from temporary testing location \\
\hline
\end{tabular}


Table A4. Indicative costs for single prototype field-testing (standardised to 6-month testing at steady-state). Note that 6 months of steady-state testing results in a project duration of 12-14 months from initiation to completion of final reporting.

\begin{tabular}{|c|c|c|c|}
\hline Project stage & $\begin{array}{l}\text { Single household } \\
\text { (6 months at steady-state; } \\
\text { total project period of } \\
12 \text { months) (ZAR) }\end{array}$ & $\begin{array}{l}\text { Community site } \\
\text { (6 months at steady- } \\
\text { state; total project period } \\
\text { of } 14 \text { months) (ZAR) }\end{array}$ & Comments \\
\hline $\begin{array}{l}\text { General and start-up } \\
\text { costs }\end{array}$ & $250000-450000$ & $350000-549000$ & $\begin{array}{l}\text { Project management and administration, review of } \\
\text { documentation, insurance, application for ethical } \\
\text { clearance, development of testing plan, training } \\
\text { on prototype with technology developer, initial } \\
\text { community engagement, community liaison officer } \\
\text { salary (for community site) }\end{array}$ \\
\hline $\begin{array}{l}\text { Site design, } \\
\text { construction and } \\
\text { testing equipment } \\
\text { procurement }\end{array}$ & $100000-296000$ & $200000-750000$ & $\begin{array}{l}\text { Excludes cost of prototype } \\
\text { Development of design basis, site infrastructure design, } \\
\text { construction and site preparation } \\
\text { Costs vary depending on complexity of prototype and } \\
\text { aims of testing }\end{array}$ \\
\hline Import and storage & $\begin{array}{c}20000-30000 \text { (logistics } \\
\text { and storage only) }\end{array}$ & $\begin{array}{c}20000-40000 \text { (logistics } \\
\text { and storage only) }\end{array}$ & $\begin{array}{l}\text { Excludes cost of prototype and cost of international } \\
\text { shipping } \\
\text { Logistics for import, duties and taxes, local storage fees } \\
\text { Duties and taxes are prototype-dependent and are } \\
\text { excluded }\end{array}$ \\
\hline Social assessment & $60000-100000$ & $70000-110000$ & $\begin{array}{l}\text { Baseline and final household surveys / focus group } \\
\text { meetings, preparation, reporting } \\
\text { May also include interim assessment for longer testing } \\
\text { periods }\end{array}$ \\
\hline $\begin{array}{l}\text { Installation and } \\
\text { commissioning }\end{array}$ & $39000-200000$ & $150000-250000$ & $\begin{array}{l}\text { Lowest costs if only front-end being tested as } \\
\text { installation is simpler, no laboratory analysis (i.e., main } \\
\text { costs are staff time and travel) } \\
\text { Longer start-up periods (e.g., for biological systems) } \\
\text { add to costs }\end{array}$ \\
\hline Testing & $400000-799000$ & $699000-1.5 \mathrm{~m}$. & $\begin{array}{l}\text { Based on 6-month test period at steady state } \\
\text { Staff time, laboratory analysis, consumables, operation } \\
\text { and maintenance, utilities, caretaker and security } \\
\text { Costs highly dependent on laboratory analyses required } \\
\text { ( } 25-50 \% \text { of testing costs could be analysis) and whether } \\
\text { an engineer is required full time on site }\end{array}$ \\
\hline $\begin{array}{l}\text { Decommissioning and } \\
\text { site rehabilitation }\end{array}$ & $60000-119000$ & $49000-150000$ & $\begin{array}{l}\text { Cost lowest for front-end only prototypes which can be } \\
\text { removed without rigging equipment; includes cost of } \\
\text { goodwill gestures as thanks for allowing testing to take } \\
\text { place }\end{array}$ \\
\hline Final project reporting & $66000-75000$ & $49000-100000$ & Can require 1-2 months of staff time \\
\hline
\end{tabular}

